\title{
LEARNING TO LIVE WITH THE “OTHER” IN AMERICA
}

\author{
Mauro Eduardo Pommer \\ Universidade Federal de Santa Catarina
}

\section{Abstract}

North-American cinema may help us understand the evolution of the concept of "otherness" as a social image. In contemporary film, it is in genres such as comedy or science-fiction that one can track the state of development of this idea on a level deeper than that shown through political correctness in more idealistic film productions.

Keywords: film comedy; otherness; documentary.

A link could be established between Michael Moore's Bowling for Columbine and Morgan Spurlock's Super Size Me that goes beyond the fact that both are bold and successful documentaries dealing with controversial aspects of contemporary life in the United States. It is a fact that both films reveal in a broad light the image that America makes of itself-and this is probably the main reason for their success, even if a lot of people do not like what they see on screen. Beneath the surface of these stories-mass murders and overgrown bodies- lies the idea of unlimited expansion that makes the fortune, and also now the fate, of the United States.

\begin{tabular}{|l|l|l|l|l|}
\hline Ilha do Desterro & Florianópolis & no 51 & p. 195 - 215 & jul./dez. 2006 \\
\hline
\end{tabular}


Since Roger and Me (1988) Michael Moore has been depicting unemployment in America-how poverty and the lack of purpose in some people's lives comes from the very fact that the USA gets richer by exporting jobs to underpaid workers in other countries. But unlimited economic expansion demands finally a high price for all to pay, even from those who profit from it. One problematic side of this search for industrial efficiency at any cost is the fact that each individual has to fit in a mold, for industrial efficiency, which leads people to be interchangeable and easily discarded. As I hope to show in this article, the expansion of body size is part of the same process, strange as this affirmation may sound at first.

Industrial and economic expansion - when considered in its actual terms-means eventually the transformation of everything into being one and the same. The deep logic of globalization is to make all nations become as one-for this is cost effective-so that you can find the same intersections, the same vehicles, the same clothes, the same shoes, the same food, convenience stores, movies, and eventually the same language no matter where you go in this vast world. To fit into this project, each individual is compelled, symbolically, to become a whole -as if he or she were simultaneously the source of all meaning-and all fruition of life came from oneself. Emotional bonds tend therefore to become gradually irrelevant.

The idea of standardizing minds and bodies for the sake of pursuing an overall industrial pattern throughout society is sold in a subtle way. In contemporary American cinema one can observe a growing effort to render "natural" the image of obese people. That is what happens for instance with Gwyneth Paltrow in Shallow Hal (Peter and Bob Farrelly, 2001), or with Eddie Murphy in the remake of The Nutty Professor (Tom Shadyac, 1996).

In these two films, bodies are presented as rebellious and invasive, capable of rejecting every normal effort to be "tamed"and yet, they appear under such circumstances as a mere "fact of nature." In an article published in Brazil, in 2004 I tried to show that this type of representation of the human body could be read both as 
an (involuntary) metaphor concerning how the American imaginary relates to America's place in the world, and a support for fantasies of violence experienced by ordinary people. ${ }^{1}$ Such fantasies of violence precisely define the portrait constructed in Michael Moore's Bowling for Columbine (2002).

The films cited above constitute the present rendering of a theme one could track from the very beginning of cinema in the USA until today, a theme I would characterize as the cinematic representation of the shifting perspective through which individuals try to incorporate the "other" as a social instance. I propose as examples for such an analysis a set of films of very different genres, which only have in common their particular dramatic intensity. We can see how this attempt to incorporate the image of "otherness" in cultural terms may acquire a character of abomination in The Birth of a Nation (David Griffith, 1915), or of an absolute and exterior othernesss, in Stagecoach (John Ford, 1939), or still as rejected incorporation in Alien (Ridley Scott, 1979). Such different moments in imaginary creation culminate in what Michael Moore shows as the contemporary relationship that an expressive part of America holds with its "other", which cannot be internalized. In response to this impasse comes a reaction of gratuitous violence, which is ironically shown by Moore as "unexplainable".

The fact that such an issue (viewed through a different bias) is also treated as comedy in other films seems, on the one hand, as a step in a new direction in order to promote the acceptance of that which is different. But on the other hand it appears as the result of the fact that one specific type of differentiation in society - the one constituted by body size - is rapidly ceasing to be casual, to become to a great extent the "norm". The news almost daily confirms the visual impression we may have: more than half of North Americans are obese, or suffer from being overweight. ${ }^{2}$

Hollywood cinema is always quick to respond to new ideological trends. In the original version of The Nutty Professor Jerry Lewis played a character who would come out from his aloofness when he falls in love with a student. The fundamental transformations he incorporated 
were in his voice and overall allure. But in the remake, Professor Sherman Klump's radical loss of weight characterizes his thinness as both scarcity and a reduction to what is mean in the human nature. So the athletic appearance of the professor's alter ego is shown in an unfavorable light and this reversal operated on the normal assumptions that fitness caused the decrease in his body size to become a synonym for moral destitution. As Sherman transforms himself into Buddy Love (in an attempt to win the heart of Carla Purty, his young and pretty colleague) he becomes aggressive and egocentric. Weight is in this case presented as not only a characteristic of the body, but also of the soul, as opposed to the superficial side of "lightness".

The longest sequences throughout the film focus on Sherman having dinner with his family. They are all obese: his mother, father, grandmother, older brother, and even the young "little" brother. Obesity is also emphasized when Sherman watches TV: as he zaps, every single channel talks of diet and weight control, in a satire focusing on the mania for this theme on current U.S. television. Falling asleep in front of his TV set, he has a nightmare where he sees himself as some type of King Kong, who remains, however, more interested in food than in the girl he might capture. Obesity is presented as a condition which is fundamentally defined in social terms by the media, instead of a basic physical property of our bodies. Therefore, more important than learning how to deal with this condition (which may become very handicapping in its most developed forms), one is led to address it as a stigma to be accepted. The final confrontation for Sherman's "soul" at the end of the story suggests that the search for one's otherness may be a dangerous mission, which should lead to the suppression of one's "rebellious" side. Under such circumstances, otherness is shown as a sort of mental state, capable of transforming someone into an arrogant and aggressive person. So, if the strategy to deal with difference in such a film attempts to incorporate difference as physical image, still the final result points to an urge to suppress its essence.

Although The Nutty Professor appears within the context of wellintentioned political correctness, it still passes far from the actual core 
of the issue. The complex question of obesity is almost reduced to a state of spirit concerning its acceptance, with no reference to the fact of its generalized presence in our society. ${ }^{3}$ Nevertheless, this film can help us speculate that when obesity is considered a public health concern as great as a dangerous epidemic ${ }^{4}$, it can also be regarded in symbolic terms as a national (and worldwide) symptom of an identity crisis. In such a perspective, to become chronically obese might derive, to a large part of the population, from a state of moral discomfort originated from the malaise of being anonymous in a mass society of the socially "invisible". Having a huge body may be regarded as a strategic development to become visible. ${ }^{5}$ Besides, what the dispute between the characters Professor Sherman and Buddy Love allegorically shows is that excessive body growth can also operate as a strategy to incorporate the "other", in order to try to be more than one actually is. In a corporeal bias, to be both oneself and the other represents to become immediately visible and recognized, and also to be self sufficient.

In a different way, Shallow Hal defines its representational strategy in a manner that can be interpreted as a dissolution of the very idea of otherness. Here, all the important characters to the story have some kind of differentiation. Since everyone is somehow special, nobody really is, which prevents the conceptual establishment of any comparison. In this case, the prevalence of difference is highlighted in such a flagrant manner that it brings about a crisis in the abstract, philosophical notion of the confrontation with otherness. Aiming at establishing a concept of a generic "other", we are supposed to reinforce our faith in individualism. This may sound liberating - but all this construction is destined to suggest that obese people continue to bear their extra weight. Basically, the representational strategy of this film is conceived in order to prove that the sense of guilt for being fat is a burden much greater to endure than the extra and unnecessary kilos.

In this movie, Rosemary is a wealthy girl who weighs 150 kilos and dedicates her life to philanthropic activities. Hal works for her father. Succumbing through the suggestion of hypnosis to pay attention exclusively to people's interior beauty, Hal falls in love with Rosemary, 
whom he visualizes with the body of Gwyneth Paltrow. In addition to this central romance, Farrellys' film presents an impressive secondary ensemble of characters burdened with physical difficulties or disabilities. Their difference is constantly emphasized, but to such an extent that their particularities are diluted: children with severe burns on their faces; a software entrepreneur whose spine is so deformed that he is only able to walk with the help of his hands; a man and a woman so ugly and socially displaced that they have problems finding sexual partners; a transvestite working as a receptionist in an elegant restaurant; a midget as a nurse in a hospital; a friend of Hal's bearing a genetic defect, consisting of a residual tale, but who shares Hal's obsession for women with sculptural bodies; Rosemary's billionaire father who, in addition to being embarrassingly ugly, has a terrible accent; two of Rosemary's colleagues in the Peace Corps, one of them with an advanced case of psoriasis, the other a Hawaiian with Down syndrome.

Amidst a similar context, the near morbid obesity of the feminine character is reduced to an irrelevant curiosity, with which society should simply become accustomed. In this sense, the "message" this film actually sends aligns side by side with a growing - though informalmovement concerning the institutionalization of obesity now present in American society.

By "naturalizing" the image of obesity, American cinema is showing us in a not very subtle way that the process of mind/body separation-essential to the establishment of industrial and military efficiency within the project of "modernization" that molded the West -has reached its acme in contemporary society. This may be convenient because it seems to allow an overall acceptance of everyone "for what we are". Bad habits currently absorbed in our society are sold to us as "unquestionable" ${ }^{7}$ : everything tends to be gigantic, including an emphasis on the growing size of the vehicles used in the congested traffic of big cities. The logical conclusion seems to be that they consume large quantities of fuel, which directly or indirectly may require armed intervention on a planetary scale to guarantee the growing demand. 
The same logic of expansion responsible for the seemingly unstoppable growth of the bodies-with reference to the occupation of space - also intensifies the use of time, since those who have a relatively stable job (a more and more problematic accomplishment) are obliged to demonstrate a similar level of productivity to that of computers, which never tire or take vacations. ${ }^{8}$ In this very competitive environment, where economic growth is not necessarily associated with job expansion (since augmentation in "productivity" is what makes the difference), people who are discarded from the work force become the only possible social image of our "other". Everyone is competing for the same jobs; and everybody tends gradually to look the same, standardized, "oversized" because of a lack of physical exercise and excessive consumption of industrialized food, as a result of endless hours performing repetitive tasks (usually in front of a computer). Like the machines that establish the pace of labor, workers become naturally interchangeable.

This is why it seems that Michael Moore's account of the events in Littleton's Columbine High School addresses the gist of the social issues brought about by standardization (of which the obesity epidemic is the most visible side, for evident reasons) by presenting the hometown of Lockheed as an exemplary microcosm for the understanding of deep America, with its chronic level of unemployment. We can read the events portrayed in Bowling for Columbine, in symbolic terms, as the assumption that each individual no longer possesses an intrinsic value as a human being (and therefore, is now reduced to being a discardable productive unit, who would be "justifiably" gunned down), and that reduces the number of candidates for the diminishing number of positions in industry-most of which, of course, have been moved to countries where labor is cheaper. In this way the horror presented by living alongside this Other (who is in fact the Same) might stop confronting the "survivors" from feeling that their aimless lives have no meaning. Those adolescents who made real their subconscious fantasies of violence-which represent the profound meaning of what is being searched for by a Nation armed to the teeth-are in fact executing a horrifying and gratuitous "poetic act" capable of rendering 
evident that our planetary society has reached a point where vacuous bloating has overtaken civilized growth.

Therefore, we witness in our time a social incapacity to define a reliable symbol frontier between Ego and Alter. The person incarnating the side of the frontier that defines "otherness" may be appointed at random, and then eliminated without any apparent motive, due simply to the psychological horror inducted by such indiscriminated coexistence. In fact, it is indispensable for our very mental health to build an image of otherness; it allows us to establish an internalized Law, in symbolic terms. But in the realm of standardization, any slight difference may appear as an excess.

A digression seems to be pertinent here on the symbolic character that can be attributed to this uncontrollable expansion in body size. Proliferation of obesity could be read, I argue, as a symptom of an identity crisis. It derives from a diffuse state of malaise, from a permanent lack of satisfaction from not being recognized, not effectively being seen "for what one is". This is why fighting this epidemic involves a change of mentality.

In a post-industrial society each individual is for each other individual a source for everything - in the economic sense, the "individual" in the classic sense has ceased to exist, since every single thing in one's life comes through commerce. Moreover, the central concept regulating economic life is no longer production, but profit. Our "other", the one with whom we trade, holds the potential to embody all Good. But, at the same time, and for the same structural reason (since we no longer exist as a member of this society without having someone to buy what we sell: which is, fundamentally, our work), such economic dependence generates a kind of absolute, paranoid fear of the omnipotent existence of this "other", both in symbolic and economic terms.

As a response to this sort of irrational fear, indiscriminated body growth may be interpreted (in regard to the filmic discourses I have been analyzing here) as a strategy to incorporate the "other", to be simultaneously oneself and someone else. Another element that could be added to this view is the observation that in affluent societies people 
have a tendency to possess too much "stuff". ${ }^{9}$ This behavior responds to a generalized fear of poverty, of smallness.

It is a remarkable fact that in our time people seldom interact with people with different professions or ways of life. The ways that cities are inhabited and evolve demonstrate a growing desire to socialize as little as possible with people from different milieux. Everyone is seen as a competitor, or a potential predator, although our type of social structure makes us all interdependent. But the dialectic competition versus cooperation requires a constant and exhaustive exercise of redefining personal frontiers, friends and foes. The enemy now seems to inhabit the same country, appearing as a surplus labour force. ${ }^{10}$ Since one feels surrounded by competitors, it may seem like a good strategy to allow the body to expand in order to acquire extra "vital space"11. Correlatively, the U.S.A. needs to be in constant expansion, and establishes its presence all over the planet. To "incorporate" someone or something into one's own life-project means, etymologically, making that person or thing become one's own body. An irrational aggressivity derives from constantly fearing the "other": when you cannot incorporate something, destroy it!

Excessive, morbid fat may be taken as the representation of a desire to preserve everything, of not letting anything go. It is an attempt to deny the natural action of time. ${ }^{12}$ Functional use of time is also a factor of stress in such a context. The accumulation of fat comes therefore in response to the guilt of not utilizing time in a lucrative manner. Time is, effectively, the only richness that we possess, the essential thing we may trade for money. And the condition of our body registers the use of the time at our disposal, which in hyper-competitive societies is fundamentally used in an attempt to overcome our competitors. Competition for markets is something to which there is no logical limit, and therefore no final victory, no time to rest. The time one dedicates to work can be measured by how far one has surpassed one's competitors. We live in an era when all moments of time become measurable by social standards, and this notion acquires catastrophic proportions when daily temporality is synchronized by the media. TV's avidity for 
continuous attention generates a sort of near desperation to ensure in programming that "each second counts", an attitude that eventually makes restlessness into a social habit. The world's gigantic merry-goround never stops turning; each instant represents a possible additional gain, or regretted loss.

Applied to the industrial production line, the logic governing the intensive use of time also contributes to create the type of nutrition that reproduces fat America. Fast food to be consumed in large quantity, without any refinement in terms of flavor. In sales management we face an analogous approach: instead of good prices, the omnipresent proposition of "take two with a discount". ${ }^{13}$ Such disposition is a natural consequence in all trade because of the pressure for a continuous increase in sales. Each firm has to sell enormously, or die a premature death as a business. Any commercial activity needs to become national, and frequently international, just to be able to continue to exist. It is the only way to cut costs sufficiently. That which is small must cease to exist, unable to compete in terms of cost cutting. Everything-since commerce is the essence of present societies-must become larger all the time.

In addition to that, merchandise is a concept that implies the definition of frontiers, a tacit acceptance of what is within and what is outside the borders establishing territories for trading. Correlatively, the notion of merchandise helps define what constitutes a person in a market society, through what belongs to him or her, and he or she is allowed to trade their labor, for instance. But when we sell all of the time available to us, our interior life becomes empty, and this lack of interiority tends to be compensated by the growing size of our body. ${ }^{14}$ Most people work an excessive number of hours, building lives and cities where everything is supposed to have a beautiful appearance. But as we observe the results of such a process over many people's bodies, the ensemble no longer looks very attractive.

Considering specifically the ideology intrinsic to the predominant religious inclination in the U.S.A., one could suggest that nutrition constitutes an unconscious and non-integrated background for 
Protestant ethics and aesthetics. First, it must be considered that Protestantism presupposes an attitude of "non-indulgence", with a permanent state of self-contention, for Paradise can be here and now if one follows the right path, that of self-restraint. Eventually, restraint will bring wealth-which appears to be a "true paradox" of this ideology-for the very concept of wealth should include an ability to spend, and ultimately "to give life" 15 , which in its final terms means spending vital force. It is true, though, that going in the reverse direction, Catholic Latin America has been unable for centuries to overcome poverty. The ability to save, introduced in America by the Puritans, makes it possible to increase the creation of wealth, fundamentally by controlling the labor of others, which is made possible through the accumulation of capital. But the continuation of such an ideology of wealth up to these days pays a price, since eating is the only "sin" Protestants can indulge in, in good conscience, for it ultimately represents a form of saving, correlate to that of accumulated capital. The insolvable contradiction, however, is that it does not allow one to act upon the lives of others, such as the accumulation of capital does. Consequently, one's own body is finally treated as being an "other" in a similar way as monetary capital is able to estrange one from oneself.

As the capitalist art form par excellence, film is a narrative device that primarily operates by capturing what is exterior to things and people. By the very nature of the apparatus, the image that comes into the frame can be separated from the object, becoming autonomous. Film is a typical product of a society where trade is the dominant force - a society that favors everything that is exterior, separable and projectable. As a conveyor of the essence of popular culture, it can provide a natural field for an analysis concerning the role capitalist culture reserves for our bodies. The construction of a body image is both an ideological and a material fact. Morgan Spurlock shows in Super Size Mehow the logic of profit shapes not only the economy of fast food but the corporeal characteristics of consumers and their health. It provides a factual account of how nutrition shapes our body. But when dealing with the formation of ideology, we face an issue far more 
difficult to detect. As in Bowling for Columbine, when Michael Moore tries to reconstruct the chain of events that might have led a couple of teenagers to commit such an unexpected and unexplainable barbarian act, all that can be established is that they went bowling, shortly before deciding to execute their plan. This "lack of an explanation" naturally leads us to believe that the true causes for such violence are diffuse, not immediately visible and require a certain distance to become distiguishable and analyzable. They are somehow connected to the very core of the national project, based on universal private possession of fire arms to protect each one from the generalized fear of each other.

What I am trying to establish here is that it is possible to trace a link between some themes treated in contemporary documentary and comedy. Spurlock is concerned with health, and addresses his subject in a factual, demonstrative basis. Moore uses irony to search for the fundamentals of violence in America. Comedies such as The Nutty Professor and Shallow Hal are concerned with the ideological building of the concept of personal image. Beneath the main themes of these four movies is a common subject: how an affluent society deals with the material and ideological construction of what may be regarded as oneself and the other. In other words, the subject is how a society built on a combination of savings and trade defines its personal and collective frontiers, and enforces them through violence. As I said above, it is possible to revisit very different approaches to this subject throughout cinema history. I would like to comment on some examples that I have already mentioned in order to explain this line of reasoning.

To Griffith, in Birth of a Nation, Afro-Americans are the "other"; to Whites, they represent the inherented danger of miscegenation, and the fear that it might degenerate family structure, therefore degrading national identity. So the "other" is represented as being abominable. Two scenes in particular show us to what extent the refusal of interracial sex and marriage is carried out, for it means that even death is preferable. One takes place during an attempted rape of a white girl by a Negro, in the southern town of Piedmont, sometime during the turbulent years following the Civil War. Flora is a teenager who walks 
alone outside her house, heading to the spring to fetch water in a bucket. Gus, an emancipated slave who became a Captain during the war, follows her. By the spring, he observes Flora with lust. Then, approaching her, he presents himself saying he is ready for marriage, and takes her hand. But after slapping him, she runs away; Gus starts to chase her. A long pursuit follows, during which Ben, former Colonel of the Confederate army and Flora's brother, notices the disappearance of his sister and starts looking for her. Feeling cornered in a rocky cliff, Flora advises Gus not to get any closer, or else she would jump. As he continues to approach her she falls off the cliff, in such a manner that it remains ambiguous whether she lost her balance or deliberately committed suicide. ${ }^{16}$ This death, for which the black Captain will have to account, joins the general sense of menace felt by the whites, that would lead according to the narration - to the creation of the Ku Klux Klan.

The other scene, that echoes this first one, is at the climax toward which the narration converges, through a parallel editing that portrays a final rescue. Hiding in an isolated cabin, Dr. Cameron (father of the young Colonel Ben), his daughter Margaret, two of their loyal black servants and Phil Stoneman (the son of the abolitionist Congressional leader) are offered shelter by two Union veterans, when persecuted by a black militia after the slaying of a Negro. As the subtitles read: "the former enemies of North and South are united again in common defense of their Aryan birthright." Meanwhile, Silas Lynch, the mulatto Lieutenant Governor, is attempting to force marriage upon Elsie, Phil Stoneman's sister. Elsie and the occupants of the cabin will eventually be saved by Klansmen at a moment when their honor and lives are in great danger. The last scene, during the rescue of those in the cabin, has a shocking image: one of the Union veterans prepares to kill his daughter with his riffle butt to prevent her from being molested by the militia. The fear of rape by Negroes in general, and of inter-racial marriage, is a recurring theme in the film, and the occasions of such menaces are responsible for the scenes of greatest impact. If the audience believes in what is shown in this explicitly racist film, one would think that the greatest ambition of Blacks (to the point of an obsession) was to have 
sexual intercourse with white women. But what the movie finally shows is the fantasy that underlines the extremist White ideology of the complete separation of the races. In this view, any attempt to live side by side with the "other" ends necessarily in tragedy, if it is not defined in strict terms and enforced by arms.

In Stagecoach, John Ford portrays a White society with more subtle shades in its individual moral positions, as represented by the microcosm gathered inside the vehicle thanks to an "aleatorial" assembling of diverse social characters. Prejudice is expressed in a very evident manner, and individual frontiers are raised in order to isolate the prostitute from socializing, as it is shown in the meal sequence during a stop in their trip. Only the fugitive from justice shows solidarity to her. Most of the individuals search to define in a rigorous manner the internal frontiers of their group. Nevertheless, in spite of their insistence on trying to establish what they regard as being proper, this is a casual assemblage of people who, in different circumstances, would certainly be themselves the object of social disapproval, according to common standards: the alcoholic doctor, the professional gambler (who is also perhaps a murderer), the corrupt banker, and even the salesman destitute of moral fiber. By having such people of questionable moral qualities sharing the same space and objective for some time, Ford shows how a nation is in fact constituted: no one can be choosy about the company they keep; and that moral standards are quite relative. On the other hand, by submitting these characters to unusual hardship, he reveals how trouble can at times contribute to bring the best out of certain people, though not out of all.

But if they are capable of forgetting for a while their personal differences when facing the "external enemy" (here represented by Native Americans), this is due to the fact that those independent and proud warriors are defined as their radically irreductible "other", who it is impossible for them to assimilate. Dealing with the same theme, in what is possibly his masterpiece, The Searchers (1956), Ford returns to the question of miscegenation in terms similar to those explored by Griffith to show, with great emphasis, that in it lies the ultimate terror 
surrounding the Whites' concern of their contact with the "other". To avoid miscegenation is the objective to which the character played by John Wayne dedicates years of his life, searching for his niece who had been captured by natives. He wants to prevent her from marrying one of them, but at the same time he lives in anguish because he does not know how to deal with his personal feelings and must face the fact that what he fears has probably already happened. A dilemma of the same nature had already been advanced in Stagecoach, during the scene in which the professional gambler saves his last bullet, even while under attack by Indians, to execute the white woman who has just given birth to a baby. In this context, the stagecoach's interior, visually opposed to the vastness of the open landscape, inevitably becomes a symbol for this closed "white" project of implanting an "autonomous", unmixed society in a territory already occupied by another "race", another culture.

In counterpoint to these visions from the founding past of the "White Nation", from which Native Americans and African Americans should be excluded, I would like to mention the "futuristic" vision presented in Ridley Scott's Alien. In this case "otherness" appears as the quality identified with capitalist greed, during a time (the 1970's) in which corporate America appears as a strange body inside the Nation, menacing to corrupt it from within. The alien, captured in its larval phase inside the belly of an astronaut (therefore an alien being who, comparatively, might also be present in the womb of the character played by Natalie Wood in The Searchers) is perceived by the corporation as an economic asset: what is most wanted is to capture its precious genetic material. But instead, what the alien does is to destroy his bearer from inside out, to exteriorize himself as a menace to the lives of the entire crew, and by extension, to the very subsistence of the human species, should his kind attack our planet.

At the center of the symbolic representation established by this film is a concern about the status of the "children of Earth". We have reached an era when dehumanizing forces characteristic of the universe of industrial work in late capitalism create such anxieties that one is 
tempted to project them upon an alien character, and a new type of heroine comes forth to expel them from the system by her individual action $^{17}$, as it is noticed by Judith Newton in "Feminism and Anxiety". This sparks an inevitable question: are we all descendants from an "inhuman mother", capable of sacrificing her own kind in order to attend foreign interests (i.e., unlimited accumulation of capital)?

A mythical figure of this devouring Great Mother haunts this narrative, as interpreted by Barbara Creed in the article "Alien and the Monstruous-Feminine". ${ }^{18}$ The lines spoken by Ash, the android character, cited by Creed, are capable of simultaneously describing the alien and the corporate administrator: "I admire its purity; a survivor unclouded by conscience, remorse or delusions of morality." The Mother-Corporation seeks its own strength by devouring her descendants through extensive unemployment combined with excessive work for those who keep their jobs. It incarnates the Big Social Other, endowed with destructive drives and capable of confusing itself with "mother-ship" Earth, in such a way that danger becomes diffuse and omnipresent. In Scott's film the alien, with its gray metallic look, is able to disappear in the dark corners of the spaceship by imitating its shape and texture - in fact, the creature and the ship are revealed, in the end, to share the same logics: a pure indifference in relation to the means to achieve their ends. They represent two aspects of the same perverted process.

Once Evil is identified, and therefore exteriorized ("Evil is amongst us", says the film subtext), its final elimination seems possible - that is how the alien is launched by Ripley in an interplanetary vacuum. As an overall meaning for this film, such identification of absolute "otherness" as an inherent constituent of corporate America (that is, from America itself as a collective enterprise) is a remarkable twist related to the American Nation as represented in popular cinema. But this is one rare and healthy exception. In the more current contemporary production of science-fiction films (to remain within this genre) we can verify a step back in terms of representation strategy in relation to that former renewal because, recently, cinema has shown a progressive 
hysteria towards a hypothetical alien invasion, as portrayed in Independence Day, Signs, Dreamcatcher or The X-Files.

In relation to Hollywood cinema, it is in the comedy genre that an interesting reflection concerning the social place of the "other" is taking place (even if we may disagree with its premises or conclusions), as I hope to have shown. In those films that deal with obesity, the new "plague" of the century, the "other" has somehow ceased to exist, becoming assimilated under the form of additional corporeality. Cinema studios react to what occurs in society, capturing movements that are already in the air, searching to reinforce them. After all, saying what people expect to hear is commonly the safest path to fat profits.

However, it is in a different type of film-shot independently from the majors, sometimes relying on European financing-that we can see a more productive unfolding of the symbolic line opened by Alien. This approach deals with a fictional treatment of the mind as the proper place of "otherness". It reveals fiction film as a privileged place for the discussion of this fundamental public issue, because the construction of the image of what is foreign to us is much more a subjective than an objective matter. This is what may be found in metaphorical terms in works such as The Blair Witch Project or Lost Highway (capable of showing more by their representational "strategies" in terms of cinematic discourse than by their thematics), that the virtual space of ideas is what actually constitutes our final frontier.

\section{Notes}

1. "O corpo no cinema como lugar de um Outro", in Estudos de Cinema Socine. São Paulo: Panorama, 2003, pp. 364-371.

2. This is, indeed, a worldwide problem, which has reached an advanced stage in the US. Concerning the Brazilian situation, the $9 / 22 / 2003$ edition of the Folha de S. Paulo newspaper registers that "In the Brazil of Fome Zero [the Governmental Zero Hunger program] there are more obese than under-nourished people". And also that "the number of obese persons has tripled during the last 30 years in our country (...) Obesity is already considered a worldwide epidemic (...) The Modern 
world seems to conspire in favor of obesity and eating disorders. People are becoming increasingly sedentary. Whether inside their cars or in front of the TV or computer, what one does most in life is to sit still (Folhateen supplement, p. 6)". Special reports on obesity proliferate in the press; the 11/27/2003 edition of the same paper published a story under the title "Morbid obesity leads youngsters to surgery", where it reads: "There are around 6.7 million obese children and adolescents in Brazil, according to the Sociedade Brasileira de Endocrinologia e Metabologia. Children and youth obesity in this country has grown $240 \%$ in the last 20 years. And the incidence of morbid obesity is leading youngsters to surgery in a radical attempt to slim down and rid themselves of illness normally associated to adults, caused by excess weight, such as hypertension, diabetes and artery blocking" (Equilibrio supplement, p. 6).

3. As happens quite frequently in Hollywood film, here the "problematic" character and his family rest isolated in the story's context as if stigmatized by narration itself. What is portrayed in the exterior shots is quite representative of this isolation. Filmed on the UCLA campus (used as a set for many films), this production quite consciously avoids realism in representing students of an American university. Nearly all extras are white and thin. This contributes to remove from the image any possible representation of actual "others" in relation to the main character and his family circle.

4. A declaration from the Centers for Desease Control and Prevention states that "one in three children born in 2000 will become diabetic unless many more people start eating less and exercising more (...) The implications are frightening. Diabetes leads to a host of problems, including blindness, kidney failure, amputation and heart disease, and diabetics are getting younger and younger" (Los Angeles Times, 06/ 15/2003, p. A36).

5. I recognize the limits for such a type of symbolic interpretation concerning a chronic problem; nevertheless, a consideration of the symbolic content of any disease is also part of the path to its cure, as Freud taught us. And this is pertinent above all to the case of epidemics, which intrinsically poses a strong social character.

6. The growing prestige achieved by competitive eating may give us an anecdotal measure of this social phenomen. In 2002, 35 events of this kind were sanctionned by the International Federation of Competitive Eating, but in 2003 there were already 75. In these competitions, hundreds of listed members of this Federation have established records such as devouring 50 hot dogs and buns in 12 minutes, 57 pan-seared cow brains (17.7 pounds of the gray matter) in 15 minutes, or 15 burritos in 8 minutes (Parade Maganize, 07/13/2003, p. 9). 
7. The disappearance of the concept of a small or middle size drink in cafeterias and fast food chains is remarkable. For example, in the Westwood Pavillion Cafeteria in Los Angeles we can only order coffee in sizes tall, grande and enorme (sic, in Spanish).

8. In an article entitled "The American vacation does a disappearing act", the Los Angeles Times signals that in times marked by recession, employee fear and guilt combined with an "overwork ethic" keep workers from taking time off. Even when they are away they are not able to relax, keeping tethered to their jobs by cell phone and e-mail. "On average, Americans get 16 days of vacation a year but take only 14 days, the survey showed. By contrast, workers in Italy average 42 annual days of vacation, the French get 37, Germans 35 and the British get 28, according to 2001 statistics from the World Tourism Organization" (07/13/2003 edition, p. L3).

9. The Los Angeles Times Magazine from 08/10/2003 presented a cover story that commented on the boom in self-storage facilities and what represents about the anxieties of American culture in uncertain times. One typical aspect of this is the compulsion felt by Americans to pay for years for the storage of things they eventually discard as useless. The text cites psychology professor Tim Kassar, author of The High Price of Materialism (MIT Press, 2002): "When people are under stress and trauma, at least in our culture, the last thing they want to do is get rid of their stuff. Their stuff provides that sort of security blanket and also a sense of identity, for better or worse. Mostly for worse, from my viewpoint." He compares America's bloated self-storage facilities to the alarming epidemic of obesity, by saying that "just as the supersized American diet has left many of us chronically overweight, materialism has led us to that moment of clarity when we realize, perhaps too late, that we are uncomfortably full (...) We live in a culture that says that the main way to [feel secure] is to have more possessions". The consequences of this attitude appear in how we live in society: "If we invest in working long hours to acquire stuff, we have less of it to focus on building meaningful relationships.We are also more likely to be competitive and objectify others as a way to get ahead and enhance status" (p. 14).

10. Christopher Lasch reminds us, in The Minimal Self, how Nazi propaganda tried to blame the growing Jewish population in Germany for the problem of unemployment, which was in fact intrinsically connected with the productivity gains originated by the extensive mechanization of industrial work.

11. This recalls the inevitable memory of the Nazi motto Lebensraum, employed to justify the annexation of neighbouring countries. 
12. As was nicely stated by Indian philosopher Jiddu Krishnamurti: "We separate living from dying, and the interval between these two is fear. One cannot live without dying."

13. Which demonstrates that, contrary to the times of early industrialization, the nature of the industrial and commercial processes became economically more relevant than the size of the product or the amount of units sold. For example: buy one pizza, get another for free. This means that transportation of raw materials, paying the rent for a store, keeping the oven heated, delivering the product, plus all commercialization costs and taxes, became incomparably more expensive than the ingredients themselves. Therefore, the amount of food consumed is no longer a fundamental criterium to define the cost.

14. In a way, what we are facing is a new era of body standardization, for most people are tendentially becoming the same size: extra-large. This is the corporeal correlation of the nearly complete industrialization of agriculture, that increasingly produces fruits and vegetables destitute of taste, to be sold to a new generation who grew up without the knowledge of what these products are supposed to taste like. In addition, there is the artificial flavoring of industrial food, that gives it a strong and appealing taste, but without any subtle natural flavour for distinction. Only the amount of food ingested counts because everything saturates the taste.

15. Regarding this lack of vitality, it is remarkable how often "B films" represent North American society as a self-reproducing colony of the living dead.

16. In his review of The Birth of a Nation, Tim Dirks suggests that "it could be interpreted that she committed suicide by jumping or leaping off the cliff to her tragic death, to avoid being raped and suffering dishonor, but it is more likely that her death is merely an accident. However, it could be interpreted that her threatened rape symbolizes the emasculation and 'rape' of whites in the South by a rampant black population suddenly emancipated - and destructive of the racial order." ( www.filmsite.org)

17. As it is noticed by Judith Newton in "Feminism and Anxiety in Alien", published in the collective work Alien Zone (organized by Anette Kuhn. London: Verso, 1990, p. 83).

18. Op. cit., p. 128-141. 


\section{References}

Associated Press. "1 in 3 Born in 2000 Are Likely to Become Diabetic, CDC Estimates". Los Angeles Times. 15 Jun. 2003, p. A36.

Clavin, Tom. "Hungry To Win”. Parade Magazine. 13 Jul. 2003, p. 8.

Clayton, Victoria. "Psychology by the Square Foot". Los Angeles Times Magazine. 10 Aug. 2003.

De Oliveira, Ana Paula. "Obesidade mórbida leva jovens à cirurgia". Folha de S.Paulo - suplemento Equilíbrio. 27 Nov. 2003.

Dirks, Tim. The Birth Of A Nation (1915). www.filmsite.org.

Engle, Janice. "The American vacation does a disappearing act". Los Angeles Times. 13 Jul. 2003, p. L3.

Kuhn, Anette, ed. Alien Zone. London: Verso, 1990.

Lasch, Christopher. The Minimal Self. New York: Norton, 1984.

Mena, Fernanda. "Gordinhos na mira". Folha de S.Paulo-suplemento Folhateen. 22 Sep. 2003.

Pommer, Mauro."O corpo no cinema como lugar de um Outro". Estudos de Cinema Socine. São Paulo: Panorama, 2003. 